\title{
O ENSINO DE MATEMÁTICA NA \\ ESCOLA NORMAL DA CORTE. (1876-1889)
}

\author{
Flávia dos Santos Soares ${ }^{1}$
}

\section{RESUMO}

No século XIX várias foram as iniciativas de selecionar candidatos ao magistério primário no Brasil. Dentre os modelos existentes estão a nomeação de professores por concursos públicos e, por outro lado, as tentativas de formação pelas escolas normais. Na cidade do Rio de Janeiro, a criação de uma escola normal ocorreu somente em 1880, após uma longa trajetória de lutas e embates. O objetivo deste texto é investigar quais eram as diretrizes para o ensino de matemática na Escola Normal da Corte, locus de formação criado para substituir a nomeação de professores por concurso. Neste artigo são feitas considerações sobre os conteúdos de matemática ministrados, os professores e as obras didáticas usadas como referência na constituição de saberes para esse novo modelo de formação de professores.

Palavras-chave: ensino de matemática; formação de professores; escola normal; século XIX.

\section{THE TEACHING OFMATHEMATICSIN THE NORMAL SCHOOLOFCOURT(1876-1889)}

\begin{abstract}
In the nineteenth century there were several initiatives to select candidates for primary teaching in Brazil. Among the existing models are the appointments of teachers for public procurement and on the other hand, attempts by the normal schools. In the city of Rio de Janeiro, the creation of a normal school in 1880 occurred only after a long history of struggles and conflicts. The purpose of this paper is to investigate what were the guidelines for teaching mathematics in the locus of training designed to replace the appointment of teachers by tender. In this article we discuss the content of mathematics taught, teachers and textbooks as a reference in the constitution of knowledge to this new model of teacher training.
\end{abstract}

Keywords: mathematics teaching; teacher training; Normal School; the nineteenth century.

\section{Introdução}

Dentre as disciplinas que compõem o currículo escolar, a matemática, juntamente com a língua materna, sempre teve lugar de destaque na configuração dos vários modelos de escola existentes no Brasil com as primeiras tentativas de escolarização da população. Sua presença pode ser notada no ensino dos jesuítas e nos termos da lei, no ler, escrever e contar; nas propostas mais elaboradas de ensino a partir do século XIX, com as tábuas para o ensino de aritmética no ensino mútuo; na formação dos militares nas academias da Marinha e do Exército; no currículo da primeira escola pública de ensino secundário do país, o Colégio Pedro II, e ainda nos exames preparatórios às escolas de direito e medicina. 
Quer para formar médicos, engenheiros, militares, advogados ou a população em geral, a matemática esteve sempre presente nas escolas. Sendo assim, a figura do professor que ensina matemática torna-se uma constante, atuando desde o ensino elementar até as faculdades. O que nos parece contraditório é que para todas essas carreiras havia cursos específicos para formação desses profissionais. Entretanto, para ser professor pouco era exigido.

Voltando aos séculos XVIII e XIX e percorrendo um caminho em direção aos primeiros passos rumo à institucionalização da instrução pública no Brasil, após a expulsão dos jesuítas, em 1759, percebe-se a existência de mecanismos regulamentando o exercício do magistério, limitados muitas vezes aos "atestados de boa conduta" e a "saber o conteúdo", sem que necessariamente fosse exigida alguma formação específica ou curso para essa capacitação, e nem mesmo atestados de escolaridade anterior.

Antônio Nóvoa (1991; 1999), lembra que inicialmente a função de professor foi desempenhada de forma subsidiária e não especializada por religiosos ou leigos que a exerciam como ocupação secundária ou complementar. Com o passar do tempo os mesmos tendem a fazer da profissão sua ocupação principal, sendo obrigados para isso a se prepararem e a se formarem. (NÓVOA, 1991).

Uma das primeiras medidas tomadas em busca da profissionalização se consistiu na definição de regras para a seleção e nomeação dos professores, com a criação de uma permissão para ensinar, cuja obtenção é obrigatória.

Este documento funciona, também, como uma espécie de "aval" do Estado aos grupos docentes, que adquirem por esta via uma legitimação oficial da sua atividade. As dinâmicas de afirmação profissional e de reconhecimento social dos professores apóiam-se fortemente na consistência deste título, que ilustra o apoio do Estado ao desenvolvimento da profissão docente (e vice-versa). (NÓVOA, 1999, p. 17 , grifos e aspas do autor).

A autorização é um documento concedido, em geral, via exame ou concurso, no qual podem se inscrever os indivíduos que apresentem certos pré-requisitos. Com isso, "os meios de seleção e de controle prevalecem amplamente sobre os meios de formação", que é adquirida não no treinamento formal, mas na prática. (NÓVOA, 1991, p.125).

Uma formação institucionalizada demorou a se concretizar e se consolidar no Brasil. É com a criação das escolas normais que o quadro precário da nomeação dos professores começa a ganhar outros rumos. Para Nóvoa (1991), as escolas normais estão na origem de uma profunda mudança dos professores primários que, por meio do ensino institucionalizado, passam de mestres pouco instruídos no início do século XIX a profissionais preparados para o exercício da atividade docente.

A reconstituição da história do ensino de matemática para a escola primária possui relevância para a recuperação dos primórdios do ensino dessa disciplina e para os debates sobre a formação de professores e, como aponta Nóvoa (1991, p.125), "sua compreensão passa sem nenhuma dúvida por uma análise do trabalho realizado no seio das escolas normais".

Em suas considerações sobre possíveis abordagens da história do ensino da matemática, Schubring (2005, p.9) destaca entre outros, o professor de matemática como o "melhor meio para ter acesso à realidade histórica do ensino". Para o autor, o professor "não constitui um sujeito passivo que recebe os programas e os faz aplicar, mas ele representa a pessoa decisiva no processo de aprendizagem” (p.9). Schubring (2005) distingue então, quatro dimensões que vão dar acesso a essa realidade, a saber: os sistemas 
de formação dos professores; as concepções das competências que os futuros professores devem adquirir; as instituições de formação e a profissionalização dos formadores nessas instituições.

Em pesquisa anterior analisamos os pré-requisitos para o exercício da profissão de professor de matemática e para a admissão aos cargos do magistério público e particular no Brasil no período do Império brasileiro, a partir do estudo dos instrumentos legais que regulamentavam esse exercício, ou seja, a legislação vigente e os sistemas de concurso. Este artigo busca avançar em outros pontos a partir da análise do ensino de matemática oferecido naquele que seria o locus de formação docente criado no Brasil para substituir a nomeação de professores por concurso: a Escola Normal.

A fim de compreender melhor como se estruturava o ensino de matemática no final do século XIX, torna-se necessário buscar informações em vários tipos de fontes. Uma delas é a legislação que regulamentava as condições de funcionamento da Escola Normal em seus primeiros anos de existência. A partir da análise de leis, decretos e relatórios dos ministros do Império, espera-se que os textos dessas normas nos levem de volta às práticas (JULIA, 2001) de maneira que possamos captar melhor o real funcionamento da escola em suas atividades cotidianas, entendendo assim o que se esperava do futuro professor.

Além da legislação, buscaram-se outros instrumentos de estudo como os programas de ensino e os compêndios escolares. Esses materiais também contribuem significativamente para a história das práticas educativas e para a compreensão da realidade do ensino de matemática, sendo portadores dos conteúdos do currículo escolar.

Há diversos textos que tratam das escolas normais e em especial da Escola Normal da Corte, entretanto há menos informações no que tange especialmente à disciplina de matemática. Usaremos os textos de Uekane (2008), Lobo (2009), Mancini e Monarcha (2002), Mancini (2005) e Villela (2003; 2008), dentre outros. Além dos trabalhos acadêmicos, consultamos os textos da legislação sobre Escola Normal da Corte na documentação localizada no Arquivo Nacional, no Rio de Janeiro.

\section{A Escola Normal na província do Rio de Janeiro}

A primeira iniciativa de criar cursos para a formação do magistério no Brasil ocorreu na província do Rio de Janeiro, em 1835, com a Escola Normal de Niterói. Sobre essa instituição os estudos de Villela (2008) nos dão conta dos fatos relacionados à sua criação e desenvolvimento.

Para ingressar na Escola Normal de Niterói, segundo a lei de abril de 1835, os candidatos deveriam ser brasileiros, maiores de 18 anos, ter boa educação, bons costumes e saber ler e escrever. Na análise de Villela (2008), o peso dos predicados morais superava os da formação intelectual do candidato, o que se pode notar tanto pelas condições de ingresso quanto pelo currículo adotado. A autora nota ainda que os conteúdos da Escola Normal não diferiam dos conteúdos das escolas públicas de instrução primária, exceto pela parte metodológica. Segundo Villela (2008), percebe-se que a intenção dos dirigentes era muito mais ordenar, controlar e disciplinar do que propriamente instruir. $\mathrm{O}$ método de ensino deveria ser o Lancasteriano ${ }^{2}$ e o diretor ensinaria:

As quatro operações de aritmética, quebrados, decimais e proporções. Noções gerais de geometria teórica e prática. Gramática da língua nacional. Elementos de Geografia. Princípios de moral cristã e da religião de estado (BRASIL. Lei n. 10 de 04 de abril de 1835, paginação irregular, grifos nossos). 
O curso não era seriado e o diretor era o único professor. Quando esse achava que o normalista estava apto, indicava-o para os exames. Após receber o diploma, o professor formado poderia então candidatar-se aos concursos das cadeiras de instrução primária que fossem abertas. (VILLELA, 2008). A demora na formação do professor e na condução do oriundo da Escola Normal às cadeiras livres suscitou críticas quanto ao modelo adotado, o que ocasionou, entre outros motivos, a desativação da Escola em $1851^{3}$.

Além da Escola Normal de Niterói, outras escolas foram sendo criadas nas demais províncias ao longo do Império, como na Bahia, em 1836; em Minas Gerais, em 1840 e em São Paulo no ano de 1863.

$\mathrm{Na}$ Corte, é a partir das décadas de 1860 e 1870 que ressurgem as discussões e debates em torno dos modelos de formação de professores: o sistema de concursos e a formação na prática com os professores adjuntos e o modelo de formação institucional por meio das escolas normais.

Como analisa Uekane (2008), para uns a Escola Normal era vista como modelo mais adequado à formação de professores para a instrução primária. Para outros, o sistema já vigente, da formação em serviço, instituído com as reformas de Couto Ferraz em 1854 ${ }^{4}$, com algumas modificações, atenderia às necessidades e ainda garantiria o menor custo.

A criação da classe dos adjuntos, ou seja, alunos que se destacam e servem de auxiliares ao professor, que efetivam sua formação na prática submetendo-se a exames periódicos, refreou o impulso das escolas normais, já existentes desde 1835. O incentivo dado de prover o magistério e aumentar o quadro de docentes desestimulou a formação institucional e valorizou a formação "em serviço".

O relatório referente ao ano de 1853, apresentado à Assembleia Legislativa pelo ministro do Império Couto Ferraz, apresenta as justificativas para a sua opção contra a Escola Normal:

O modo prático de se formarem professores era uma necessidade, para cuja satisfação mais se instava pela reforma [...]. Esta necessidade, pois, não podia deixar de ser atendida no regulamento [...]. Não se adotou porém nele o meio admitido em diversos paises, mas que vem sendo condenado em outros: falo das escolas normais [...]. Sem pessoal habilíssimo e dedicado para manter e dirigir uma instituição de tal ordem, e tendo diante dos olhos o exemplo das escolas normais, estabelecidas em algumas províncias, que nenhum fruto deram por causa daquela falta, pareceria por sem dúvida imprudente arriscar grandes somas, e perder inutilmente o tempo preciso para no fim de alguns anos suprimir-se a escola que se criasse (BRASIL. Relatório do Ministro dos Negócios do Império, 1854, p.63-64).

As escolas normais acabaram por serem desprestigiadas pelos alunos visto que os mesmos poderiam chegar ao magistério em menos tempo e sem a necessidade de frequentar aulas. Villela (2003, p.126) lembra ainda que os defensores da Escola Normal se mostravam contrários ao modo como os professores eram admitidos ao cargo do magistério pondo em dúvida a seriedade dos concursos:

[...] não é por acaso que muitas escolas normais se extinguiram ou viveriam de forma agonizante a partir de então. As reclamações dos diretores dessas escolas vão se referir, constantemente, às dificuldades que encontram para manter um curso [...] quando em contrapartida, pessoas muito despreparadas ascendem ao magistério por concursos que não fazem maiores exigências e, muitas vezes, já têm seus candidatos "esperados" (ficando rotulados como "concursos de palácio"). 
Nesse contexto, os concursos orais e escritos assumiam o papel definidor das capacidades profissionais reforçando a idéia de que apenas o conhecimento do conteúdo era suficiente para a seleção de bons mestres.

Mesmo com deficiências os sistemas de concursos prevaleceram frente às instituições de formação institucional. O modelo dos concursos estimulava a formação "na prática", fazendo com que os exames adquirissem a função não só de selecionar, mas também de qualificar e titular o profissional docente. Desse modo, a "formação" do professor era deixada de lado, incentivando um modelo de seleção deficiente que nem sempre escolhia adequadamente aqueles aptos ao exercício do magistério.

Em algumas províncias, antes da criação de escolas normais, foi criado um curso normal anexo aos liceus existentes, com o acréscimo de uma cadeira de pedagogia ao currículo e a parte prática devendo ser exercida em alguma escola pública primária. Essa foi uma das formas elegidas para simplificar o processo de qualificação profissional, aproveitando-se a formação geral fornecida pelos estabelecimentos de ensino secundário. Mas, nesse modelo não há de fato preocupação com saberes específicos para os futuros professores.

A primeira iniciativa em prol da fundação de uma Escola Normal na Corte veio da iniciativa particular de um grupo de professores juntamente com o Conselheiro Manoel Francisco Correa. A escola foi inaugurada em 25 de março de 1874 e tinha como fim "dar em um curso pedagógico o ensino theorico e prático indispensável às pessoas que se destinam ao magistério da instrução primária”. (BRASIL. Relatório do Ministro dos Negócios do Império, 1874, p.17). O curso era gratuito, com duração de três anos e deveria funcionar a partir das $5 \mathrm{~h}$ da tarde, não excedendo às $9 \mathrm{~h}$ da noite. $\mathrm{O}$ currículo estava organizado da seguinte forma:

$1^{\circ}$ ano: Língua nacional (gramática elementar); Pedagogia; História Sagrada; Aritmética Elementar e Metodologia decimal; Desenho e Música.

$2^{\circ}$ ano: Língua Nacional (ensino mais desenvolvido); Pedagogia; Geografia em Geral e Corografia ${ }^{5}$ do Brasil; Aritmética; Noções de Física e Química; Desenho e Música.

$\underline{3^{\circ} \text { ano: }}$ Filosofia; Álgebra até equações do $2^{\circ}$ grau, e Geometria Aplicada às artes; História em Geral, e particularmente do Brasil; Noções de História Natural; Noções de Higiene e fisiologia; Noções de Medicina Doméstica, primeiros socorros médicos; Noções de Direito Público Constitucional. (Apud UEKANE, 2008, p.187, grifos nossos).

Para entrar na Escola poderiam se candidatar aqueles que fossem maiores de 14 anos, dessem provas de moralidade, soubessem ler e escrever corretamente, a doutrina cristã e as quatro operações fundamentais da aritmética. Entre os membros do corpo docente da escola estava Luiz Pedro Drago, professor de matemática do Colégio Pedro II, e autor de compêndios didáticos ${ }^{6}$. Apesar das propostas inovadoras a Escola funcionou apenas por um ano.

Novas tentativas de instituir uma Escola Normal na Corte ressurgiram em $1876 \mathrm{com}$ o decreto $n^{\circ} 6379$ de 30 de novembro. Inicialmente a proposta era de criação de uma escola para o sexo masculino e outra para o sexo feminino em um curso com três anos de duração. Os conteúdos de matemática figuram no $1^{\circ}$ e $2^{\circ}$ ano do curso compreendendo o ensino de "Arithmetica até logarithmos, algebra até ás equações do $2^{\circ}$ gráo, geometria plana, metrologia e regras de escripturação mercantil; [...] metrologia: systema legal de pesos e medidas". (BRASIL. Decreto $\mathrm{n}^{\circ} 6379$ de 30 de novembro, 1876, p.1144). A disciplina 
seria ministrada por um mestre próprio, ao contrário do que ocorria na Escola Normal de Niterói em sua fundação.

Por falta de condições para a manutenção da mesma, a criação da Escola foi adiada para 1879, como parte do decreto 7247 de 19 de abril que reforma o ensino primário e secundário na Corte e superior no Império. A formação de professores por meio das escolas normais fica estabelecida no artigo $9^{\circ}$ e em seu currículo constava o ensino de aritmética, álgebra e geometria; metrologia e escrituração mercantil. O decreto ainda garantia preferência aos alunos formados na Escola Normal para o preenchimento de cadeiras públicas, medida tomada para tentar forçar todos os que atuavam no magistério primário a frequentar as aulas do novo modelo de formação proposto e, assim, legitimar a formação institucional.

\section{A Escola Normal da Corte}

Após uma longa trajetória de lutas e embates que vinham desde as primeiras décadas do século XIX,em 1880, o estabelecimento destinado à formação dos professores primários foi finalmente instalado por meio do decreto n. 7684. A Escola Normal, agora única e mista, apresentava um curso sem duração definida, dependendo apenas da aprovação dos alunos em exames, a exemplo de outras instituições de ensino secundário.

A Escola Normal foi tardiamente instalada na Corte e, como lembra Mancini e Monarcha (2002, p.4) "era uma instituição que não obteve um desenvolvimento harmônico e contínuo, passando por um processo de ensaios e fracassos, ora abrindo, ora fechando suas portas, até conseguir a sua implantação definitiva". A partir daí, as múltiplas experiências de estabelecimento de escolas normais nas províncias, iniciadas com a fundação de uma Escola Normal em Niterói, passam a tomar por referência orientações vindas do Rio de Janeiro. (KULESZA, 1998).

Com o surgimento de um curso destinado à formação escolarizada do professor, com a Escola Normal da Corte, a expectativa era de eliminar gradativamente a seleção de professores para a escola primária que ocorria mediante a realização de concursos, tão logo o número de professores formados fosse suficiente. Assim, os saberes relacionados às disciplinas ensinadas na escola primária, apontados nos exames para o magistério sofrem mudanças. (MANCINI, 2005). Em especial, interessa-nos avaliar de que forma os saberes para a disciplina de matemática se constituíram nesse novo modelo de formação.

O primeiro regulamento da Escola Normal da Corte previa o ensino de português; francês; matemáticas elementares e escrituração mercantil; elementos de cosmografia, geografia e história universal; geografia e história do Brasil; elementos de ciências físicas e naturais, e fisiologia e higiene; filosofia e princípios de direito natural e de direito público; princípios de economia social e doméstica; pedagogia e prática do ensino primário em geral; pedagogia e prática do ensino intuitivo ou lições de coisas; princípios de lavoura e horticultura; instrução religiosa. $\mathrm{O}$ artigo $3^{\circ}$ complementava o currículo com as seguintes matérias: caligrafia, desenho linear, música vocal, ginástica, prática manual de ofícios para os meninos, e trabalho de agulha para as meninas.

Um ano depois, o decreto n. 8025, de 16 de março de 1881, traz alterações ao funcionamento da Escola Normal estabelecendo dois cursos: o de ciências e letras e o de artes.

No curso de ciências e letras estudar-se-iam instrução religiosa; português; francês; matemáticas elementares; corografia e história do Brasil; cosmografia, geografia e história universal; elementos de mecânica e de astronomia; ciências físicas; ciências biológicas; 
lógica e direito natural e público; economia social e doméstica; pedagogia e metodologia; noções de agricultura. $\mathrm{O}$ curso de artes oferecia as disciplinas de caligrafia e desenho linear; música vocal; ginástica; trabalho de agulha (para as meninas). A matemática se destacava por fazer parte do curso de ciências e letras, claramente privilegiado frente ao curso de artes. Apesar disso, por meio da documentação localizada, pode-se perceber que o programa da Escola para a disciplina de desenho linear contemplava tópicos que hoje são estudados na disciplina de matemática no ensino fundamental e médio.

O currículo da Escola tinha a intenção de ultrapassar os conhecimentos ensinados na escola elementar substituindo "o velho mestre-escola pelo novo professor primário". (NÓVOA, 1991, p. 125). Para tal buscava-se formar professores a partir de um conjunto de saberes que os distanciassem da formação pela prática, incentivada pela reforma de Couto Ferraz de 1854. A formação proposta pelas escolas normais deveria colocar os alunos em contato com os discursos científicos emergentes julgados necessários para a constituição de um cidadão e para instituir uma especificidade na formação do professor, até então caracterizado como autodidata.

Os professores deveriam lecionar os saberes necessários à formação dos mestres, descritos no regulamento, que serviam como base para a elaboração dos programas de ensino das cadeiras. Esses programas eram organizados em pequenas brochuras de capas de diferentes cores nas quais constava o conteúdo da cadeira e a assinatura do professor regente.

Segundo o regulamento de 1881, na primeira séria estudar-se-ia "Arithmetica: estudo completo, theorico e pratico" e na segunda série do curso, "Álgebra, geometria e trigonometria: álgebra até equações do $2^{\circ}$ gráo a uma incognita inclusive. Geometria elementar, estudo completo; exercicios e problemas; noções de trigonometria rectilinea". A parte de escrituração mercantil foi suprimida em comparação ao regulamento de 1880 . Além de conteúdos de matemática, há também a cadeira de elementos de mecânica e de astronomia. (BRASIL. Decreto n. 8025 de 16 de março de 1881, p.189).

Os programas deveriam ser confeccionados anualmente e depois aprovados pela Congregação. Pelos documentos localizados pode-se notar que alguns programas eram somente retificados, com poucas alterações, feitos "em cima" do programa do ano anterior. Isso não era proibido pelo regulamento. A única condição é que os programas fossem aprovados anualmente pelo ministro do Império.

No Arquivo Nacional tem-se acesso aos programas das cadeiras de arithmética $(1882,1884,1885,1886,1887)$, caligraphia e desenho linear $(1883,1884,1885,1886,1887)$, e de álgebra, geometria e trigonometria $(1885,1886,1887)$.

Sobre os programas de ensino algumas observações podem ser feitas. Tomemos, por exemplo, a disciplina de aritmética. Para o ano de 1882, a disciplina se dedica ao estudo do sistema de numeração; números inteiros, suas propriedades e operações; frações ordinárias e decimais; números complexos; razões e proporções; progressões e logaritmos. Com pouquíssimas alterações esse programa permaneceu o mesmo nos anos seguintes, até 1887. O programa de matemática da $1^{\mathrm{a}}$ série deveria ser cumprido em aulas ministradas às 2 as $^{\text {as }}$, $4 .^{\text {as }}$ e $6 .{ }^{\text {as }}$ feiras que tinham duração de 1 h e $15 \mathrm{~min}$, passando à $1 \mathrm{~h}$ de duração em 1886 . Em comparação com o programa de ensino do Colégio Pedro II, para o mesmo ano, nota-se bastante semelhança. (VECHIA; LORENZ, 1998). Entretanto, no Colégio Pedro II esse programa era proposto em partes, ao longo de três anos de estudo. Assim, pode-se dizer que os estudos na Escola Normal se configuravam como bastante exigentes em relação a essa disciplina. Esse é um dos motivos que pode explicar, por exemplo, o reduzido número de alunos que se inscreviam para os exames de aritmética e dos poucos aprovados. (BRASIL, Relatório do Ministro dos Negócios do Império, 1887). 
Antes do fim do Império, em 1888 (Decreto 10.060), o currículo é organizado em três anos de estudo, mas sem a divisão em dois cursos. O ensino de matemática elementar é ramificado em duas cadeiras: aritmética e álgebra elementar e geometria. A matéria de elementos de mecânica e de astronomia é suprimida e volta a figurar o ensino de noções de escrituração mercantil, para os alunos.

\section{Benjamin Constant e os professores da Escola Normal da Corte}

Em todas as iniciativas de criação de uma Escola Normal pode-se notar a presença de conteúdos de matemática na configuração desse novo modelo de formação de professores. Na Escola Normal da Corte, um fato a ser destacado é a indicação de Benjamim Constant Botelho de Magalhães como diretor interino, em março de 1880, o que imprime destaque ao ensino das matemáticas e deixa clara a orientação positivista ${ }^{7}$ conferida à nova Escola:

a quantidade de matérias prescritas para serem ensinadas na Escola Normal intentava imprimir um caráter mais científico à formação de um novo profissional, para que este se diferenciasse dos antigos professores primários, que não mais traziam os resultados desejados quanto ao desenvolvimento da instrução. Entre as matérias definidas para a instituição se inseriam as das escolas primárias sendo que, na Escola Normal, seriam ensinadas de maneira mais aprofundada, prestando-se atenção especial à metodologia de ensino. (UEKANE, 2008, p. 39).

A trajetória de Benjamin Constant no magistério, como aponta Lemos (1999), apesar de intensa e duradoura, é cheia de períodos de instabilidade e sucessivas frustrações em suas tentativas de ingressar no magistério público ${ }^{8}$. Obteve sucesso quando prestou seu segundo concurso para o Instituto Comercial em 1863, embora em 1862 já tivesse sido nomeado como professor de matemáticas elementares do Imperial Instituto dos Meninos Cegos. Nessa instituição, Benjamin Constant contribuiu para o ensino de matemática para o qual fez adaptações do programa à matéria e elaborou um resumo de álgebra elementar que depois foi convertido para o Braille. (LEMOS, 1999).

A saída de Benjamin Constant do Instituto Comercial, o que o levou a sua entrada na Escola Normal, também não deixou de ser confusa. Em novembro de 1879, ele foi informado pela Inspetoria de Instrução Primária e Secundária do Município da Corte, por meio de um decreto baixado no mesmo mês, que a cadeira de matemáticas do Instituto havia sido suprimida, juntamente com as de francês, inglês, alemão e caligrafia. (LEMOS, 1999).

Em março de 1880, Benjamin Constant foi nomeado interinamente como diretor e professor de matemáticas elementares e escrituração mercantil na Escola Normal, segundo Lemos (1999), como uma espécie de prêmio de consolação. Somente em 1881 passaria a diretor efetivo. Entre idas e vindas na Escola Normal, assumindo a direção por duas vezes, deixou a mesma definitivamente em maio de 1889.

Adepto do positivismo, Benjamim Constant tentava imprimir a doutrina em suas aulas:

Quando, em 15 de maio de 1880, um sábado, iniciou as aulas de aritmética, estava decidido a ministrar o curso aos futuros professores primários segundo o plano didático positivista, o único que merecia sua adesão. Durante as três primeiras aulas fez considerações introdutórias para relacionar o assunto da cadeira com as demais ciências. Era o mesmo método que adotava nas aulas de mecânica na Escola Politécnica, onde uma introdução geral situava a matéria na "escala enciclopédica das 
ciências", elaborada pelo "gênio de A. Comte". Em seguida, desenvolvia todo o programa da escola segundo a teoria matemática positivista. (LEMOS, 1999, p. 293, aspas do autor).

Em trecho do próprio Benjamin Constant, anotado em uma caderneta, tem-se demonstração de sua prática docente nos princípios positivistas:

\begin{abstract}
7 de julho de 1880. - Escola Normal - Tratei hoje da adição dos números inteiros - O Pozitivismo - Ésta sábia e abençoada doutrina a que devo tantos benefícios, sejão quais forem os sacrifícios que me traga, que me imponha no empenho solene que tomo de seguir e cumprir fielmente os seus preceitos, dominará eternamente, tanto na vida pública como na vida privada, todos os meus sentimentos, pensamentos e atos. (assinado) Benjamin Constant Botelho de Magalhães. (MENDES, 1937, p. 148).
\end{abstract}

Além de Benjamim Constant outros nomes ocuparam as cadeiras de matemáticas elementares, entre efetivos e substitutos.

Para a inauguração da Escola Normal em 1880, os professores foram nomeados interinamente para as cadeiras previstas no regulamento. Dentre os docentes convidados estavam muitos professores do Instituto Comercial e do Colégio Pedro II. Ao contrário da Escola Normal de Niterói, na qual o diretor era o único professor, cada uma das 12 cadeiras tinha um professor regente, além dos substitutos para cada uma das seis seções nas quais estavam organizadas as disciplinas (Art.38). (BRASIL, Decreto n.7684 de 06 de março, 1880, p.194).

Para a disciplina de caligrafia e desenho linear estava à frente o professor Paulino Martins Pacheco. Pacheco era engenheiro, foi delegado de instrução pública, diretor dos cursos mantidos pela Sociedade Auxiliadora da Indústria Nacional, professor do Colégio Pedro II e do Instituto Comercial. Outro docente, Cândido Baptista Antunes, era professor público e foi contratado para servir de mestre auxiliar, devido ao grande número de matrículas para a $1^{\mathrm{a}}$ série em 1880 .

Em 1881, o novo regulamento, suprimiu algumas cadeiras e acrescentou outras. Benjamim Constant, que regia a cadeira de matemáticas elementares e escrituração mercantil, assumiu a cadeira de elementos de mecânica e de astronomia, ficando a cadeira de matemáticas elementares com o ex-professor de geografia e história do Brasil, Carlos Maximiliano Pimenta de Laet.

Carlos Maximiliano Pimenta de Laet (1847 - 1927) foi jornalista, professor e poeta brasileiro nascido no Rio de Janeiro. Pimenta de Laet foi ex-aluno do Colégio Pedro II, instituição em que obteve seu diploma de bacharel em letras. Formado em engenharia pela Escola Politécnica tornou-se professor catedrático de português do Colégio Pedro II em 1873, onde também ocupou o posto de diretor do Internato. Fora, ainda, deputado e membro da Academia Brasileira de Letras.

Tanto Benjamim Constant como Carlos Maximiliano Pimenta de Laet, entre outros, são exemplos dos nomes de pessoas ilustres que ocuparam cargos de professores da Escola Normal. Dentre os docentes das variadas disciplinas pode-se encontrar, por exemplo, jornalistas, políticos, artistas, militares e médicos. Essas personagens:

[...] se destacaram pelas ideias defendidas ou trazidas para o país em periódicos da época, o lhes garantiu papel de grande evidência no cenário social da Corte e das províncias, sendo muitas vezes reconhecidos por sua contribuição para a instrução e, consequentemente, para o desenvolvimento e consolidação do Império. (UEKANE, 2008, p. 51). 
No quadro de vencimentos dos professores da Escola Normal para o ano de 1884, localizado no Arquivo Nacional, consta também o nome de Alfredo Coelho Barreto para a cadeira de matemáticas. Barreto era positivista e pai de Paulo Barreto, o João do Rio. Na década seguinte seu nome figura na relação de professores catedráticos do Colégio Pedro II na cadeira de mecânica e astronomia. É ele quem assina os programas de ensino das disciplinas de aritmética, álgebra, geometria e trigonometria dos anos de 1884, 1885, 1886, 1887 localizados no Arquivo Nacional. Outro nome é o de Manuel Arthur Ferreira como regente da cadeira de caligrafia e desenho, que também vem a ser professor catedrático do Colégio Pedro II em 1895. (BRASIL. Anuário do Colégio Pedro II, 1954).

\section{Compêndios para a Escola Normal}

Juntamente com os programas das disciplinas propostos para cada ano, havia uma indicação de compêndios a serem adotados. Uma investigação a respeito dos livros utilizados pela Escola Normal da Corte permite-nos, como diz Corrêa (2000, p.13),

[...] pensar na possibilidade de uma aproximação maior do ponto de vista histórico acerca da circulação de idéias sobre o que a escola deveria transmitir/ensinar e, ao mesmo tempo, saber qual concepção educativa estaria permeando a proposta de formação dos sujeitos escolares.

Os livros didáticos representam um importante aliado dos professores e nos fornecem, juntamente com os programas de ensino, informações que ajudam a "entender a instituição escolar por dentro, já que esse tipo de material é portador de parte dos conteúdos do currículo escolar naquilo que diz respeito ao conhecimento". (CORRÊA, 2000, p.13).

Uma das atribuições da Congregação era indicar as obras e os compêndios para as disciplinas na Escola e submetê-los a aprovação do Ministro do Império (BRASIL. Decreto 8025 de 16 de março de 1881, 1881). A análise dos programas para as cadeiras de aritmética; álgebra, geometria e trigonometria, bem como para a de desenho linear, nos fornece uma relação de livros indicados e adotados na Escola.

Para o ano de 1882, o professor Pimenta de Laet indica para a cadeira de aritmética o compêndio de Serrasqueiro, Tratado Elementar de Arithmética, em sua $4^{\text {a }}$ edição. José Adelino Serrasqueiro era português nascido em 1835, bacharel formado em medicina e filosofia pela Universidade de Coimbra e professor de matemática no liceu da mesma cidade. A primeira edição do Tratado de Aritmética é de 1869. Segundo Henriques (2005) a obra de Serrasqueiro está inserida numa fase em que os manuais procuravam atualizar a organização e a escrita da matemática baseada numa lógica de ensino decorrente da preocupação crescente com a didática. A inclusão de exercícios no final das diversas seções nos livros de Serrasqueiro apresenta-se como aspecto inovador, que rompe definitivamente com a forma exclusivamente expositiva dos conteúdos. Serrasqueiro propõe uma coleção completa de livros para o ensino secundário adotados também no Colégio Pedro II na década de 1890. O conteúdo do livro, conforme a edição consultada (SERRASQUEIRO, 1919), segue em essência o que se propõe o programa da disciplina, com exceção do capítulo destinado aos números incomensuráveis.

Para os anos de 1884, 1885, 1886 e 1887 são indicadas as aritméticas de Condorcet e Ottoni.

O livro conhecido como "Aritmética de Condorcet" é o livro didático Moyes dápprendre à compter sûrement et avec facilité, publicado após a morte do autor em março 
de 1794. Segundo Gomes (2001), no Brasil houve pelo menos duas edições do livro de Condorcet, sendo a primeira em português editada pela Livraria Nicolau Alves com o título Methodo para aprender a contar com segurança e facilidade em 1883, e a segunda em francês publicada em 1903. A aritmética que consta no livro trata "essencialmente da representação dos números do sistema decimal indo-arábico, e das operações com esses números, efetuadas por intermédio de algoritmos que aproveitam todas as vantagens desse sistema”. (GOMES, 2001, p. 130). O manual é constituído em duas partes: a primeira em doze lições, para o aluno, e a segunda com recomendações ao professor.

A "Aritmética de Ottoni " "é um dos livros de Cristiano Benedito Ottoni (1811-1896) nascido no Rio de Janeiro e considerado o pai das estradas de ferro no Brasil por ter sido o primeiro diretor da Estrada de Ferro Dom Pedro II. (OTTONI, 1983). Era engenheiro, foi professor da Escola Politécnica e examinador de matemática de concursos de professores primários e secundários no período do Império. Publicou diversos livros de aritmética, álgebra, geometria e trigonometria que foram utilizados no Colégio Pedro II e no ensino público e privado em todo o país e se constitui como a primeira referência nacional da matemática escolar. (VALENTE, 1999).

Para a $2^{\mathrm{a}}$ cadeira da $2^{\mathrm{a}}$ série do curso, álgebra, geometria e trigonometria, sob responsabilidade do professor Alfredo Coelho Barreto, os livros indicados para os anos de 1884 e 1885 foram a álgebra e a trigonometria ${ }^{10}$ de Ottoni e a geometria de Clairaut.A obra de Alexis Claude Clairaut, Eléménts de Géométrie é marcada pela preocupação em relacionar a matemática com contextos práticos, na tentativa de se colocar como uma opção em substituição aos Elementos de Euclides de modo a dar significado aos seus axiomas e postulados. (NASCIMENTO, 2010). Segundo Miorim:

preocupado em romper com a tradicional apresentação dos conhecimentos geométricos por meio de um método que pudesse ao mesmo tempo motivar e auxiliar na compreensão, Clairaut encontrou na historia o fio condutor para a sua obra. Não o fez, entretanto, através da reconstituição detalhada das descobertas geométricas, mas por meio de um caminho - que poderia ter sido aquele percorrido pelos descobridores - que apresentasse essas descobertas como soluções encontradas pelos homens na tentativa de resolver os problemas que a eles se apresentaram. Por entender que os mais antigos problemas - como a própria origem da palavra geometria parece indicar - estavam relacionados à questão de medida de terras, escolheu esse tema como o elemento gerador das descobertas geométricas. (1998, p.46).

Além dos livros indicados nos programas de ensino das disciplinas, outros documentos sugerem que outros compêndios eram comprados para a consulta das normalistas, servindo de apoio ou de leitura complementar para as aulas.

No Arquivo Nacional foram localizadas notas fiscais da compra de livros para a Escola adquiridos Livraria Alves \& Co, nas quais constam outros títulos de obras de Matemática tais como: o compêndio de Trigonometria, de Serrasqueiro, que não é indicado nos programas; Elementos de Álgebra, dos irmãos Antônio Gabriel de Morais Rego e Alfredo Cândido de Morais Rego e Elementos de Álgebra, do português Augusto José da Cunha. Ainda foram compradas algumas obras em francês como Elements de Géométrie descriptive por FIC (Fréres de l'Instruction Cherétienne) e os volumes 6 e 7 da Histoire des Sciences Mathematiques, de Maximilien Marie.

Para o ensino do desenho linear, os programas localizados indicam o curso elementar de desenho linear como compêndio. A obra, de autoria do próprio professor da Escola Normal Paulino Martins Pacheco, teve sua primeira edição publicada provavelmente em 
$1879^{11}$. (ZUIN, 2001). Na análise de Elenice Zuin, a obra insere-se dentre os manuais escolares de desenho linear de autores brasileiros nos quais o foco é o estudo das construções geométricas. Segundo a autora, nesses livros, a teoria da geometria plana se resume em algumas definições e propriedades, ou as construções geométricas se apresentam como num catálogo, mas, não são fornecidas justificativas para as construções (ZUIN, 2001). Ainda segundo ZUIN (2001, p.123):

Este modo de tratar as construções geométricas, desligadas da teoria da geometria plana, não é uma característica apenas dessa obra, estando também presente em outros livros didáticos de Desenho. [...] Deste modo, o programa proposto no livro caracterizou e reforçou o ensino do desenho linear: construções sem Justificativas, presas aos passos de construção, que não levam a um entendimento da teoria. $\mathrm{O}$ aluno precisa decorar os procedimentos para realizar novamente uma determinada construção.

Ao que tudo indica, o livro Curso de Desenho Linear Geométrico teve boa aceitação tendo sido adotado também no Colégio Pedro II.

\section{Considerações Finais}

Como observam alguns autores (MANCINI, 2005; KULESKA, 1998) não há dados concretos que afirmem o nível em que estavam inseridas as escolas normais, dado o seu duplo caráter de escolas secundárias e profissionais. Por um lado os programas das matérias que eram ministradas na Escola Normal da Corte em muito se assemelhavam aos conteúdos exigidos pelos concursos públicos, que por sua vez se assemelhavam aos conteúdos da escola primária. Nota-se também, pelos compêndios recomendados, a preocupação em adotar livros de autores renomados e já adotados em outras instituições importantes, como o Colégio Pedro II.

A Escola Normal da Corte orientava sua avaliação pelo modelo dos exames parcelados, como fazia o Colégio Pedro, mas ao contrário deste, não possibilitava o acesso ao ensino superior, mas habilitava à carreira de professor primário.

Ao final do Império, o ensino normal do Brasil configura-se com uma forma de renovar e qualificar os professores que atuavam na escola primária. Embora com vários obstáculos em sua implementação notou-se na Escola Normal da Corte a intenção em promover um ensino diferenciado para os futuros professores, o que pode ser visto pela documentação existente como currículos, compêndios, horários e outros.

Mas assim como outras escolas normais criadas nas províncias, a Escola Normal da Corte, em sua fase inicial, teve de se acomodar ao ensino secundário ministrado nos liceus, dirigidos ao público masculino e estruturados para preparar o estudante ao ensino superior que "constituíram referência fundamental para o desenvolvimento do ensino normal, emprestando seus professores, suas instalações e seus regulamentos para as novas escolas" (KULESKA,1998, p.63). Dessa forma, o nascimento da Escola Normal se apresenta bastante vinculado ao ensino secundário existente, espelhando-se no Colégio Pedro II, adotando os mesmos compêndios e muitas das orientações para o ensino dadas no colégio de referência. 


\section{Referências}

BASTOS, Maria Helena Câmara. O ensino mútuo no Brasil (1808-1827). In: BASTOS, Maria Helena Câmara; FARIA FILHO, Luciano Mendes de (Orgs). A escola elementar no século XIX: o método monitorial/ mútuo. Passo Fundo: Ediupf, 1999. p. 95-118.

CORREAA, Rosa Lydia Teixeira. O livro escolar como fonte de pesquisa em História da Educação. Cadernos Cedes, Campinas, ano XIX, n. 52, p. 11-24, nov. 2000.

GOMES, Maria Laura Magalhães. Um livro didático da França iluminista: a Aritmética de Condorcet. Zetetikè, Campinas, v.9, n. 15-16, p. 119-153, jan./dez. 2001.

HENRIQUES, Helena Castanheira. Os livros de Matemática durante a monarquia: um breve roteiro. In: MOREIRA, Darlinda; MATOS, José Manuel (Orgs.). História do Ensino da Matemática em Portugal: Actas do XIII Encontro de Investigação em Educação Matemática. Beja: Sociedade Portuguesa de Ciências da Educação, 2005. p. 181-198.

JULIA, Dominique. A cultura escolar como objeto histórico. Tradução de Gizele de Souza. Revista Brasileira de História da Educação. Campinas, n. 1, p. 9-43, jan./jun. 2001.

KULESZA, Wojciech Andrzej. A institucionalização da Escola Normal no Brasil (18701910). Revista Brasileira de Estudos Pedagógicos, Brasília, v. 79, n.193, 1998, p. 63-71.

LEMOS, Renato. Benjamin Constant: vida e história. Rio de Janeiro: Topbooks. 1999.

LÔBO, Yolanda Lima. A Escola Normal da Corte: tensões entre a realidade e o proclamado. In: CHAVES, Miriam Waidenfeld; LOPES, Sonia de Castro (Orgs.). Instituições educacionais da cidade do Rio de Janeiro: um século de história (1850-1950). Rio de Janeiro: Mauad; FAPERJ, 2009, p.83-99.

MANCINI, Ana Paula Gomes; MONARCHA, Carlos. Escola normal da corte (18761889): contribuição para o estudo das instituições de formação de professores no Império. CONGRESSO BRASILEIRO DE HISTÓRIA DA EDUCAÇÃO, II. Anais ..., Natal, 2002, paginação irregular. Disponível em:

www.sbhe.org.br/novo/congressos/cbhe2/pdfs/Tema3/0339.pdf. Acesso em: 21 de abril de 2010 .

Escola normal da corte (1876/1889): um estudo por meio de fontes

documentais. Marília, 2005. Tese (Doutorado em Educação) - Faculdade de Filosofia e Ciências, Universidade Estadual Paulista, Marília, 2005.

MENDES, Teixeira. Benjamin Constant: esboço de uma apreciação sintética da vida e obra do Fundador da República Brazileira. Rio de Janeiro: Imprensa Nacional, 1937.

MIORIM, Maria Ângela. Introdução à história da Educação Matemática. São Paulo: Atual, 1998.

NASCIMENTO, Demilson Benedito do. A Geometria e o Princípio da Complementaridade: análise de concepções. ENCONTRO BRASILEIRO DE ESTUDANTES DE PÓS-GRADUAÇÃ̃O EM EDUCAÇÃO MATEMÁTICA, XIV. Anais..., Campo Grande, 2010, paginação irregular. Disponível em: http://ebrapem.mat.br/inscricoes/trabalhos/GT02_Nascimento_TA.pdf. Acesso em: 5 de março de 2011.

NÓVOA, Antônio. Para o estudo sócio-histórico da gênese e desenvolvimento da profissão docente. Teoria \& Educação, Porto Alegre, n. 4, p. 109-139, 1991. 
O passado e o presente dos professores. In: NÓVOA, Antônio (Org.). Profissão Professor. 2. ed. Porto: Porto Editora, 1999, p.13-34.

OTTONI, Cristiano Benedito.Autobiografia. Brasília: Editora da Universidade de Brasília, 1983.

SCHUBRING, Gert. Pesquisar sobre a história do ensino da matemática: metodologia, abordagens e perspectivas. In: MOREIRA, Darlinda; MATOS, José Manuel (Orgs.) História do Ensino da Matemática em Portugal: Actasdo XIII Encontro de Investigação em Educação Matemática. Beja: Sociedade Portuguesa de Ciências da Educação, 2005, p. 520.

SERRASQUEIRO, José Adelino. Tratado Elementar de Arithmetica. 20. ed. Coimbra: Livraria Central de J. Diogo Pires - Sucessoras, 1919.

UEKANE, Marina Natsume. Instrutores da Milícia cidadã: a Escola Normal da Corte e a profissionalização de professores primários (1854-1889). Rio de Janeiro, 2008. Dissertação (Mestrado em Educação) - Faculdade de Educação, Universidade do Estado do Rio de Janeiro, Rio de Janeiro, 2008.

VALENTE, Wagner Rodrigues. Uma História da Matemática Escolar no Brasil (17301930). São Paulo: Annablume/Fapesp, 1999.

VECHIA, Ariclê; LORENZ,Karl Michael (Orgs). Programa de Ensino da Escola Secundária Brasileira:1850-1951.Curitiba/PR: Editora do Autor, 1998.

VILLELA, Heloísa. O mestre-escola e a professora. In: LOPES, Eliana Marta Teixeira; FARIA FILHO, Luciano Mendes; VEIGA, Cynthia Greive. 500 anos de educação no Brasil. 3. ed. Belo Horizonte: Autêntica, 2003, p. 95-144.

. A primeira escola normal do Brasil: concepções sobre a institucionalização da formação docente no século XIX. In:ARAUJO, José Carlos Souza; FREITAS, Anamaria Gonçalves Bueno de; LOPES, Antônio de Pádua Carvalho (Orgs.). As escolas normais no Brasil: do Império à República. Campinas: Alínea, 2008, p.217-231.

ZUIN, Elenice de Souza Lodron. Da régua e do compasso: as construções geométricas como um saber escolar no Brasil. Belo Horizonte, 2001. Dissertação (Mestrado em Educação) - Faculdade de Educação, Universidade Federal de Minas Gerais, Belo Horizonte, 2001.

\section{Documentos Oficiais e Legislação}

ARQUIVO NACIONAL. Série Educação. Ensino Primário. Documentos Diversos. BRASIL. Anuário do Colégio Pedro II - v.XV, 1949-1950. Rio de Janeiro, 1954.

BRASIL. Decreto n. 1.331A de 17 de fevereiro de 1854. Approva o Regulamento para a reforma do ensino primário e secundário no Município da Côrte. Coleção das Leis do Império (1808-1889). Disponível em: http://www2.camara.gov.br/atividadelegislativa/legislacao/publicacoes/doimperio. Acesso em: 27 de março de 2011.

BRASIL. Decreto n. 6.379 de 30 de novembro de 1876. Crêa, no Município da Corte, duas escolas Normaes primarias. Coleção das Leis do Império (1808-1889). Disponível em: http://www2.camara.gov.br/atividade-legislativa/legislacao/publicacoes/doimperio. Acesso em: 27 de março de 2011. 
BRASIL. Decreto n. 7.247 de 19 de abril de 1879. Reforma o ensino primário e secundário no município da Corte e o superior em todo o Império. Coleção das Leis do Império (18081889).Disponível em: http://www2.camara.gov.br/atividadelegislativa/legislacao/publicacoes/doimperio. Acesso em: 27 de março de 2011.

BRASIL. Decreto n. 7.684 de 06 de março de 1880. Crêa no municipio da Côrte uma Escola Normal primaria. Coleção das Leis do Império (1808-1889). Disponível em: http://www2.camara.gov.br/atividade-legislativa/legislacao/publicacoes/doimperio. Acesso em: 27 de março de 2011.

BRASIL. Decreto n. 8025 de 16 de março de 1881. Manda executar o novo Regulamento para a Escola Normal do Município da Corte. Coleção das Leis do Império (1808-1889).

Disponível em: http://www2.camara.gov.br/atividadelegislativa/legislacao/publicacoes/doimperio. Acesso em: 27 de março de 2011.

BRASIL. Decreto n. 10.060 de 13 de outubro de 1888. Dá novo Regulamento à Escola Normal. Coleção das Leis do Império (1808-1889). Disponível em:

http://www2.camara.gov.br/atividade-legislativa/legislacao/publicacoes/doimperio. Acesso em: 27 de março de 2011.

BRASIL. Lei n. 10 de 04 de abril de 1835. Cria uma Escola Normal da Província do Rio de Janeiro. Coleção de Leis Decretos e Regulamentos da Província do Rio de Janeiro. Rio de Janeiro. Disponível em: http://www.infoiepic.xpg.com.br/hist_ato10.htm. Acesso em: 27 de março de 2011.

BRASIL. Ministério do Império. Ministro (Luiz Pedreira do Couto Ferraz). Relatório do ano de 1853. Apresentado à Assembléia Geral na $2^{\mathrm{a}}$ sessão da $9^{\mathrm{a}}$ Legislatura, 1854.

Disponível em: http://www.crl.edu/pt-br/brazil/ministerial/imperio. Acesso em 7 de agosto de 2010.

BRASIL. Ministério do Império. Ministro (João Alfredo Corrêa de Oliveira). Relatório do ano de 1873. Apresentado à Assembléia Geral na $3^{\mathrm{a}}$ sessão da $15^{\mathrm{a}}$ Legislatura, 1874.

Disponível em: http://www.crl.edu/pt-br/brazil/ministerial/imperio. Acesso em 7 de agosto de 2010.

BRASIL. Ministério do Império. Ministro (Ambrosio Leitão da Cunha). Relatório do ano de 1886. Apresentado à Assembléia Geral Legislativa na $2^{\mathrm{a}}$ sessão da $20^{\mathrm{a}}$ Legislatura, 1887. Disponível em: http://www.crl.edu/pt-br/brazil/ministerial/imperio. Acesso em 7 de agosto de 2010.

\section{Notas}

\footnotetext{
${ }^{1}$ Professora da Faculdade de Educação da Universidade Federal Fluminense, Mestre em Matemática e Doutora em Educação pela Pontifícia Universidade Católica do Rio de Janeiro (PUC-Rio).

${ }^{2} \mathrm{O}$ método foi recomendado para a instrução pública no Brasil com a lei de 15 de outubro de 1827 . Segundo Bastos (1999), o monitorial system ou méthode mutuelle, nome adotado na França, baseia-se no ensino dos alunos por eles mesmos. Todos os alunos da escola estão reunidos num vasto local, sob a direção de um só mestre. A característica principal para o "sucesso" do método é a participação dos alunos. As classes eram dirigidas por um monitor, ou seja, um aluno em estágio mais "avançado" de aprendizagem que se destacava aos olhos do professor dentro de uma classe e "aprendia" mais rápido a lição. Antes do início da aula, o professor dava indicações e orientações particulares para o monitor que, durante a aula, transmitia aos demais colegas o que lhe havia dito o professor e fazia-os repetir a lição até que estes a soubessem de cor. Entretanto, cada aluno pode pertencer ao mesmo tempo a várias classes diferentes, ou seja, pode estar mais avançado em leitura do que na escrita ou no cálculo (BASTOS, 1999).

${ }^{3}$ A Lei de 4 de fevereiro de 1859 recriou a Escola Normal. Mais informações consultar, dentre outros, Villela (2008).
} 


\footnotetext{
${ }^{4}$ Decreto n. 1331A de 17/02/1854 e outros.

${ }^{5}$ Estudo ou descrição geográfica de um país, região, província ou município.

${ }^{6}$ Luiz Pedro Drago é autor da obra Apostillas de Álgebra publicada no Rio de Janeiro pela Typografia de Pinheiro \& C., em 1868. Na documentação localizada no Arquivo Nacional não consta indicação desta obra nos Programas, embora seja possível que o próprio autor a tenha utilizado em suas aulas.

${ }^{7} \mathrm{O}$ plano de estudos proposto em 1881 distribuía os estudos científicos segundo a ordem estabelecida pela classificação das ciências de Augusto Comte.

${ }^{8}$ Por diversas vezes prestou concurso público sendo aprovado em primeiro lugar, mas outras pessoas foram nomeadas sem concurso. Em outras ocasiões, entraves burocráticos o impediram de assumir as vagas ou apenas era nomeado interinamente às cadeiras a que concorria.

${ }^{9}$ A obra em questão é Elementos de Arithmetica, publicado pela Eduardo \&Henrique Laemmert. Tanto nos Programas da Escola Normal encontrados no Arquivo Nacional como nos Programas para o Colégio Pedro II organizados por Vechia\&Lorenz (1998) a indicação dos livros é feita apenas citando o sobrenome do autor. No Programa para a Escola Normal para o ano de 1884 tem-se ao final da página apenas "Algebra - Ottoni, Geometria - Clairaut, Trigonometria - Ottoni".

${ }^{10}$ Elementos de Álgebra ( $1^{\mathrm{a}}$ edição de 1852 publicada pela Eduardo \&Henrique Laemmert).

Elementos de Trigonometria Rectilinea ( $1^{\mathrm{a}}$ edição de 1853 publicada pela Eduardo \&Henrique Laemmert).

${ }^{11}$ A obra Compêndio de Dezenho Linear do mesmo Paulino Martins Pacheco figura como referência para o ensino dessa cadeira no Programa do Colégio Pedro II no ano de 1878. (VECHIA\&LORENZ, 2008). No anexo B do trabalho de Zuin (2001) há referências de um parecer sobre a obra datado de 1879.
}

Recebido em

março-13

Aprovado em outubro-13 